\title{
Práticas educativas nas instituições de acolhimento sob o olhar das crianças
}

\section{Educational practices at shelter institutions from children's perspective}

\author{
Eliane Lima PISKE \\ Maria Angela Mattar YUNES² \\ Angela Adriane BERSCH ${ }^{3}$ \\ Angela Torma PIETRO 4
}

\begin{abstract}
Resumo
Este artigo apresenta uma pesquisa calcada na Bioecologia do Desenvolvimento Humano que analisou instituiçóes de acolhimento sob o olhar das crianças de 7 a 12 anos. Para tanto, realizou-se coleta documental, inserçáo ecológica e entrevistas reflexivas associadas ao registro fotográfico simultâneo. A metodologia priorizou a escuta atenta e o diálogo, respeitando a integridade, os valores morais e culturais da dinâmica das crianças em instituiçóes. Para análise dos dados, foi utilizada a Teoria Fundamentada nos Dados com apoio do software Atlas. Ti. Resultados indicam que o lugar é percebido como disciplinar, de imposiçáo de regras, de privaçáo e ambivalências nas práticas educativas.
\end{abstract}

Palavras-chave: Instituições. Percepção das Crianças. Infâncias. Análise Bioecológica.
Abstract

This article presents a research grounded in the Bioecology of Human Development which analyzed shelter institutions through the perceptions of children aged 7-12 years. Documentary research, ecological engagement and reflexive interviews associated with simultaneous photographic record were used during the investigation. The methodology focused on the listening practices and dialogue with children aiming torespect their integrity, moral and cultural values whilelivingin institutions. Data analysis was based on the principles of Grounded Theory with support of Atlas.ti software. Results revealed that institution is perceived by them as a place of discipline, imposition of rules, deprivation and ambivalences in educational practices.

Keywords: Institutions. Perception of Children. Childhoods. Bioecological Analysis.

1 Pedagoga. Mestre e Doutoranda pelo Programa de Pós-Graduação em Educação Ambiental pela Universidade Federal do Rio Grande (PPGEA/FURG). Bolsista da Coordenação de Aperfeiçoamento de Pessoal de Nível Superior (CAPES). Grupo de Estudos Ecoinfâncias- infâncias, ambientes e ludicidade. Colaboradora do Centro de Referência em Apoio à Família (CRAF/FURG). Avenida Itália, s/n, km 8. Tel.: (53)991555339 E-mail: <e.nanny@hotmail.com>.

2 Psicóloga. Mestre em Psicologia do Desenvolvimento pela University of Dundee, Escócia. Doutora em Educação, Psicologia da Educação (PUC/SP), Pesquisadora do CNPq. É professora permanente nos Programas de Pós-Graduação em Psicologia Social na Universidade Salgado de Oliveira, Universo, Niterói, RJ e professora colaboradora no Programa de Pós-Graduação em Educação na Universidade La Salle, UNILASALLE/Canoas, RS e aposentada da Universidade Federal do Rio Grande/FURG. Fundadora do Centro de Estudos Psicológicos sobre Meninos e Meninas de Rua - CEPRUA da FURG e coordenadora do Centro de Referência e Atenção às Famílias e Profissionais Sociais - CRAF/UniversoUnilasalle. Bloco A, R. Marechal Deodoro, 217- Centro, Niterói- RJ. E-mail: <mamyunes@yahoo.com.br>.

3 Doutora e Mestre em Educação Ambiental - Programa de Pós-Graduação em Educação Ambiental da Universidade Federal do Rio Grande (PPGEA/FURG). Professora Adjunta do Instituto de Educação da Universidade Federal do Rio Grande (IE/ FURG). Grupo de Pesquisas e Estudos Ecoinfâncias - Infâncias, ambientes e ludicidade e Grupo de Pesquisa e Estudos em Educação, Cultura, Ambiente e Filosofia. Avenida Itália, s/n, km 8. Tel. (53) 999538870. E-mail: <angelabersch@gmail.com>.

4 Doutora e Mestre em Educação Ambiental - Programa de Pós-Graduação em Educação Ambiental da Universidade Federal do Rio Grande (PPGEA/FURG). Professor Assistente do Curso de Direito da Faculdade Anhanguera Educacional LTDA. Professor Colaborador do Curso de Pós-Graduação Lato Sensu Abordagem Multidisciplinar em Dependência Química. Desenvolve projetos no Núcleo de Direitos Humanos e Cidadania da Faculdade Anhanguera do Rio Grande. Coordenadora do Projeto de Prevenção a Violência do CRAF (Centro de Referência e Apoio à Família). Coordenadora da Proteção Especial de Média Complexidade da Secretaria Municipal de Cidadania e Assistência Social. Rua Dr. Pedro Armando Gatti, 94. Tel. (53)991512799. E-mail: <angela.torma@gmail.com>.

\begin{tabular}{l|l|l|l|l|l|} 
R. Educ. Públ. & Cuiabá & v. 27 & n. 66 & p. $905-923$ & set./dez. 2018 \\
\hline
\end{tabular}


A violência assola e causa medo, principalmente quando as vítimas são seres indefesos como crianças. $\mathrm{Na}$ busca de protegê-las, o Estado as ampara em instituições, ambientes que reúnem em convivência diária um número de acolhidos com costumes e hábitos diversos. Este estudo buscou explicitaras vozes pouco ouvidas, na defesa da necessidade de um trabalho interdisciplinar com as instituiçóes de acolhimento, contextos encarregados de receber e cuidar de crianças e adolescentes em condições vulneráveis. As expressóes crianças em situação de risco e crianças em situação de vulnerabilidade são muito usadas para classificar crianças que vivem diferentes espectros de dificuldades. Mas cabe ressaltar que não são sinônimos. Quando se vive em condiçóes vulneráveis, o risco existe como possibilidade. Em condições de risco, há concretude expressiva de processos que podem trazer efeitos negativos e ameaçadores (YUNES; SZYMANSKI, 2005).

A inquietação que motivou essa pesquisa foi a seguinte: como são as instituiçóes de acolhimento sob o olhar das crianças- que lugar é esse? A investigação objetivou gerar uma compreensão das percepçóes de crianças acerca do acolhimento institucional sob o paradigma da perspectiva bioecológica de desenvolvimento humano. A escassez de literatura motivou ainda a seguinte indagação: como se sentem as crianças que vivem no ambiente institucional? Entende-se que apenas a partir das vozes das crianças sobre o microssistema institucional de relaçóes tornase possível compreender a vida institucional para dar protagonismo a quem tem esse direito, ou seja, as próprias crianças.

Importante mencionar que a violência envolve condicionantes que prendem as vítimas, seus familiares, amigos e a comunidade numa teia de múltiplos nós górdios. A busca de açôes sociais coletivas para que esses sistemas de agressão ou de agressores recebam a penalidade e não vitimizem crianças/adolescentes é um grande desafio. Quando a agressão ocorre no seio familiar e as crianças são encaminhadas às instituiçôes de acolhimento, a situação é ainda mais complexa. Por isso, urge compreender as instituiçóes de acolhimento sob o olhar de crianças que efetivamente vivem essas situaçôes de risco pessoal e social.

Portanto, esse estudo buscou pesquisar e analisar bioecologicamente as instituições de acolhimento por meio da voz e do olhar de crianças de 7 a 12 anos. Aliado ao principal objetivo da pesquisa, os específicos foram: investigar a percepção das crianças acerca da dinâmica do funcionamento do ambiente institucional; compreender a rotina desse ambiente a partir das inter-relaçóes das observaçóes; e mapear falas dos profissionais e das crianças. O contexto de participantes da pesquisa foi situado em duas instituiçóes: uma de acolhimento governamental e outra não governamental. A escolha das instituiçóes teve como critério um levantamento do maior número de acolhimentos de crianças na faixa etária de 7 a 12 anos na época da coleta de dados. 
As dificuldades socioambientais do acolhimento institucional sob o olhar das crianças em situação de risco pessoal e social são relevantes para os estudos do campo da educação ambiental e vêm mobilizando pesquisadores de diversas áreas. Entretanto, é notório que, dentre tantos grupos de estudos no Brasil, poucos trazem a visão bioecológica do ambiente pelo ponto de vista das crianças. Um estudo que mais se aproxima da presente investigação pesquisou a percepção de crianças sobre suas relaçóes com os cuidadores que trabalham nas instituiçóes num município do extremo sul (MARZOL; BONAFÉ; YUNES, 2012). O objetivo era melhor compreender o que as crianças julgam ser bons cuidadores, além de suas expectativas sobre essas interaçóes. Silva e Magalhães (2011) realizaram uma pesquisa que parte do cotidiano de uma criança adotada, produzindo os significados sobre o processo de acolhimento institucional ao interagirem durante uma brincadeira (SILVA; MAGALHÃES, 2011).

É consenso que refletir e estabelecer um diálogo com as crianças possibilita a participação delas na pesquisa. As crianças são atores sociais e é preciso valorizar positivamente sua relaçáo com o outro ao compartilhar vivências, inventividades, medos e desejos num processo dialógico e permeado por socializar, ver, ouvir, interpretar, produzir, apropriar, dialogar e fazer entre os pares (CORSARO, 2011).

$\mathrm{Na}$ revisão de trabalhos que pesquisam os condicionantes socioeconômicos davulnerabilidade social a partirdaabordagembioecológica do desenvolvimento humano no Brasil destaca-se que há poucos estudos construídos sobre os olhares das crianças e dos seus interesses e expectativas durante o acolhimento institucional (AI), o que demonstra a necessidade de mais estudos que possam contribuir para a compreensão do tema. A abordagem bioecológica prioriza conhecer a vida em ambiente natural e, portanto, os contextos são estudados juntamente e simultaneamente com os condicionantes socioambientais sob a percepçáo das crianças participantes da pesquisa e dos profissionais que trabalham no ambiente institucional. A visão aqui construída está ancorada em autores críticos e reflexivos que reconhecidamente apresentam grande competência e experiência sobre esse fenômeno em sua complexidade (SIQUEIRA; DELL'AGLIO, 2006; MARZOL; BONAFÉ; YUNES, 2012; BERNARDI, 2010).

Paradoxalmente ao baixo número de trabalhos sobre o acolhimento institucional focados na escuta da criança acolhida, temos o contraste com os números assustadores de acolhimentos no Brasil, conforme mostram os dados do Levantamento Nacional das Crianças e Adolescentes em Serviço de Acolhimento (LNCASA): 
Participaram do presente Levantamento Nacional 2.624 Serviços de Acolhimento Nacional (SAI), dispersos em 1.157 municípios brasileiros (que representam 20,8\% do total, localizados nas 27 unidades de federação. Os SAI pesquisados têm capacidade de atendimento de 52.587 crianças e adolescentes. No momento da pesquisa, estes serviços tinham 36.929 crianças e adolescentes acolhidos. (ASSIS; FARIAS, 2013, p. 82).

O olhar ecológico/sistêmico sobre o acolhimento institucional evidencia ainda a importância de estudar e analisar fenômenos associados ao contexto. É preciso observar os dados por diferentes lentes. $\mathrm{O}$ elevado número de crianças e adolescentes que permanecem institucionalizados náo deve ser desmerecido. Ainda, salienta-se que não se pode partir de sentimentos negativos ou de incapacidades, mas é fundamental focar o olhar no potencial de cada criança e no que elas têm para contar sobre os locais de acolhimento. Ressaltar as possibilidades de cada contexto se constituir em um ambiente de proteção é outro importante indicador a ser considerado.

Ao pesquisar o contexto institucional, almeja-se o ganho secundário de promoção de qualidade de vida para as crianças que vivem nas instituiçóes, pensando que bons tratos nas interaçóes sociais são elementos fundamentais ao desenvolvimento humano (BARUDY; DARTAGNAN, 2007). Nessa esteira, salienta-se o campo da educação ambiental (EA) e seus conceitos essenciais para a compreensão e desenvolvimento de novas estratégias para lidar com as vicissitudes desse fenômeno social. Assim, questóes que envolvem o acolhimento institucional nesta pesquisa são dimensões importantes nos estudos em educação ambiental, porquanto trata de um fenômeno que diz respeito à sociedade em sua totalidade. Ademais, é uma temática que requer urgência nas ações e para possibilitar que as crianças reflitam e (re)pensem seus futuros, tendo claro que o acolhimento institucional é uma passagem social e histórica e transitória. Portanto, a busca se direciona da pesquisa para soluções, açóes e planejamento de intervençóes preventivas e protetivas.

Nesse sentido, a metodologia que investiga o mundo sob o olhar das crianças gera uma pesquisa com menor risco de resultados informativos e técnicos. As estratégias metodológicas buscam sentimentos e expressóes de emoçóes advindas da oportunidade de dialogar sobre o contexto institucional de maneira reflexiva, participativa e dialógica. Dialogar implica em ouvir e falar, ponderar, parar, olhar e tentar entender os contextos, ancorados numa postura freireana: "[...] os sujeitos se encontram para a transformação do mundo em colaboração." (FREIRE, 1996, p. 237). Essa atitude é fundamental para fazer a relaçâo do que se observa, escuta e registra na realização de uma pesquisa com as crianças. 


\section{Procedimentos do encaminhamento metodológico}

A pesquisa foi realizada numa cidade do extremo Sul do Brasil, em duas instituições de acolhimento, uma instituição governamental e outra não governamental. Elas serão denominadas Instituição de Acolhimento 1 e Instituição de Acolhimento 2. Partindo da abordagem ecológica e amparada nos estudos do pesquisador e teórico Urie Bronfenbrenner (1996), foi possível questionar as pesquisas realizadas fora do ambiente natural e dissociadas de suas realidades e escolher a inserção ecológica (CECCONELLO; KOLLER, 2004; PRATI et al., 2008) como um dos caminhos a serem transitados no contexto pesquisado. Esse e outros caminhos metodológicos no desenvolvimento dessa pesquisa foram os seguintes:

\section{Participantes:}

Participaram sete crianças de ambos os sexos com idades entre 7 e 12 anos. Elas foram identificadas por nomes fictícios escolhidos por elas mesmas: duas meninas da Instituição 1 pediram para serem identificadas pelo nome das mães (ambas falecidas), Elizangela e Maria Izabel. Na Instituição 2, as crianças escolheram nomes de personagens: dois meninos de 12 anos optaram por Veterano e Hills; os dois de 7 anos pediram para serem chamados por Elsa e Bob; e uma menina de 9 anos por Princesa.

\section{Inserção ecológica nas entidades de acolhimento}

Foram pesquisadas as especificidades de cada ambiente e, sobretudo, observamos e ouvimos informalmente as crianças institucionalizadas. $\mathrm{O}$ diário de campo foi a estratégia de registro das observações naturalísticas. As inserçóes nas instituiçóes de acolhimento foram realizadas a partir de visitas sistemáticas e planejadas em horários e turnos diversos, além de horário integral (manhã, tarde e noite). $\mathrm{O}$ estudo se fez pautado num olhar direcionado para as crianças e suas características biopsicológicas, além de focar o processo e a experiência delas nos contextos e nos processos proximais/relacionais.

Os processos proximais são relaçóes entre as pessoas e os seus contextos imediatos e são produtores de desenvolvimento humano. A inserção ecológica (CECCONELLO; KOLLER, 2004; PRATI et al., 2008) é um método de pesquisa qualitativa que prioriza que investigadores estabeleçam interações proximais com os participantes da pesquisa para melhor compreenderem os processos, as 
pessoas, o tempo e suas açôes cotidianas. A inserção ecológica (CECCONELLO; KOLLER, 2004; PRATI et al., 2008; SILVEIRA et al., 2009) foi uma aliada metodológica indissociável na pesquisa e tem como base teórica a Bioecologia do Desenvolvimento Humano de Urie Bronfenbrenner (BRONFENBRENNER, 1996). As anotaçóes no diário de campo e as inserçóes no ambiente foram fundamentais ao estudo.

\section{Entrevistas reflexivas e registro fotográfico simultâneo}

No intuito de ouvir e dialogar com a criança sobre sua percepçáo do acolhimento, numa perspectiva coletiva e contextual do ambiente, a entrevista reflexiva possibilitou diálogo com os participantes da pesquisa sobre os conceitos, formas de acolhimento, consequências e reflexóes sobre as entidades de acolhimento. Aliada à entrevista, utilizou-se o registro fotográfico simultâneo, que foi realizado pelas próprias crianças no ambiente institucional, e foram elas que interpretaram as imagens.

As crianças apresentam um ponto de vista particular a respeito dos fatos que merecem ser ouvidos por múltiplas linguagens. A pesquisa qualitativa trabalha com significados, motivaçóes, vivências e cooperaçóes, que possibilitam escutar verdadeiramente os participantes da pesquisa (MINAYO, 1996). Por essa razão, utilizamos a entrevista reflexiva associada ao recurso da máquina digital, simultaneamente, para que o diálogo fosse mais profundo e acurado com as crianças, o que aconteceu na própria instituição, em data e hora previamente combinadas com elas e com os coordenadores da Instituição 1 e Instituição 2.

A entrevista reflexiva apresenta alguns procedimentos indispensáveis: aquecimento, questóes desencadeadoras, questôes de esclarecimento e devoluçáo (SZYMANSKI, 2004). Essas etapas foram seguidas para garantir uma reflexão que possibilitasse novos atos diante das problematizaçóes: "nos procedimentos da entrevista reflexiva são previstos pelo menos dois encontros para que uma relação reflexiva seja construída." (YUNES; SZYMANSKI, 2005, p. 123). Isso vem ao encontro da pesquisa realizada por Garzella (2008), inspiradora dos procedimentos de métodos ora adotados que seguiram as fases a saber, na sequência: "um grupo de apresentaçáo da pesquisa para as crianças; entrevista individual com cada criança; produção de fotos com câmera digital por cada criança; discussão com as crianças sobre as fotos produzidas." (GARZELLA, 2008, p. 27).

Portanto, a pesquisa buscou trazer à tona duas formas de linguagem e expressóes das crianças: a linguagem oral - na entrevista reflexiva- e a linguagem fotográfica - por meio dos registros fotográficos das crianças sobre a instituição. Os detalhes sobre os procedimentos são a seguir explicitados. 
No primeiro momento, foi realizada uma conversa inicial individual para apresentar os objetivos da pesquisa e o tema em estudo, consistindo num aquecimento com a apresentação da pesquisa para a criança. Um diálogo desencadeador sobre as vidas das crianças na instituição foi realizado: "conteme um pouco da sua vida aqui na instituição..." Nessa etapa foi entregue uma máquina digital para que a criança fotografasse o que quisesse sobre sua vida na instituição. Seguindo-se ao momento inicial, outras questóes esclarecedoras foram propostas, após a análise da primeira entrevista individual e análise da produção de fotos com câmera digital por cada criança. Nesse momento, tão importante quanto as demais fases da pesquisa, fizemos a devolução, em que foi exposta uma préanálise mais conclusiva dos dados que puderam ser interpretados pela própria criança e pelo pesquisador. As crianças tomaram conhecimento do material que foi produzido em todas as etapas antes citadas.

A flexibilidade da entrevista reflexiva associada ao registro fotográfico simultâneo permitiu aprofundar elementos que foram surgindo e sendo construídos durante o encontro. Tal fato é consoante com a proposta da pesquisa de compreender que lugar é esse que se chama instituição de acolhimento para as crianças. A entrevista mostrou-se efetivamente reflexiva e as crianças puderam refletir sobre suas colocaçóes, dialogando e contando sobre suas vidas nas instituições de acolhimento. Tal fato converge com as colocaçóes de Yunes e Szymanski:

A proposta da entrevista reflexiva supóe um encontro interpessoal que inclui a subjetividade dos protagonistas, que juntos vão construir um novo conhecimento mediante o encontro de seus mundos sociais e culturais numa condição de horizontalidade e equilíbrio das relaçóes de poder. (YUNES; SZYMANSKI, 2005, p. 122).

Importante reiterar que a entrevista reflexiva associada ao registro fotográfico simultâneo aconteceu em momentos distintos e em dias alternados. Todas as etapas foram realizadas no panorama individual para manter a privacidade e evitar a exposição de questóes íntimas e pessoais ao grupo, em conformidade com a metodologia adotada: "nesta interação pode-se suscitar informaçóes objetivas e subjetivas, bem como conduzir um diálogo para que o tema em questão possa ser aprofundado." (YUNES; SZYMANSKI, 2005, p. 123).

No segundo encontro, as fotos registradas pelas crianças foram visualizadas na tela do computador e o diálogo surgiu com algumas questóes iniciais. No terceiro encontro, as crianças continuaram manifestando suas percepçôes, opinióes e seus desejos, dialogando e expressando o que gostavam ou não nas instituiçóes de acolhimento. 
No último encontro, foram apresentados os relatos anteriores e as crianças puderam discordar, tendo a oportunidade de acrescentar ou contribuir com novas informaçóes. As fotografias tiradas registraram as características físicas do lugar e, sobretudo, possibilitaram que as crianças refletissem ao interpretá-las, compartilhando suas percepçóes e dilemas sobre o acolhimento institucional. Vale mencionar que todos os momentos foram conduzidos pelas crianças, de modo que elas foram manifestando suas percepçóes com a oportunidade de refletirem sobre as colocaçóes.

Como a pesquisa teve um delineamento qualitativo,a análise dos dados seguiu os princípios da Grounded-theory (GLASER; STRAUS, 1967; STRAUS; CORBIN, 1990; YUNES, 2001). Sob o escopo desses princípios, os dados emergiram das respostas e dos registros das crianças, que ofereceram subsídios para a organização e codificação das informaçóes obtidas na pesquisa com o apoio do software Atlas. Ti (SAN MARTÍN, 2014). Esse é um recurso que permite identificar códigos, reuni-los e dar início à identificação das categorias a partir do mergulho nos dados e nas subcategorias qualitativas que emergem com a apreciação das informaçóes, sem as categorias empíricas. Na sequência, foi realizada a interpretação dos dados na perspectiva do pesquisador com a construção dos metatextos.

$\mathrm{O}$ Atlas. Ti permitiu analisar os termos pela maneira que apareceram, criando-se as amarraçóes com as informaçóes, as palavras e as expressóes que levavam a identificar as categorias e, sucessivamente, as subcategorias (ARIZA et al., 2015). O Atlas.Ti, ferramenta tecnológica organizada pelos princípios da Grounded-theory, é também conhecido como Teoria Fundamentada nos Dados (CHARMAZ, 2009), o que sugere uma forma de análise baseada nos dados, ou seja, as informaçóes qualitativas obtidas na pesquisa foram registradas e organizadas de acordo com os subsídios.

\section{Resultados}

Os dados da pesquisa foram construídos e alicerçados com as crianças numa permuta de afeto e de escuta atenta. Isso foi possível devido ao uso de uma metodologia dialógica, reflexiva e participativa. O diálogo foi fundamental para categorizar as informaçóes a partir do uso do Atlas. Ti e da Teoria Fundamentada, que foram imprescindíveis para triangular as categorias e subcategorias.

"Isso aqui pra mim é uma casa que eu gosto muito. É um orfanato onde fica as crianças que náo têm, tipo ta desabrigada, um pouco pelas mães [...] É um tipo, tipo deixa eu vê, não sei explica. E onde as crianças ficam e ficam por pouco tempo aqui, e nas audiências elas vão embora, umas vão embora outras ficam e todas as audiências que teve aqui eu fiquei." (VETERANO, 2015). 
Começamos por esse relato na intenção de apresentar como é o diálogo sobre o lugar com as crianças que passam, permanecem e as que ficam por anos nas instituiçôes. Nas palavras de Veterano, que está institucionalizado há cinco anos, é clara a percepção das instituições de acolhimento como lugares transitórios para uns e permanentes para outros. Essa realidade constitui uma das categorias, a de lugar físico, juntamente com um enredo de códigos resultantes do software Atlas. $T i$, conforme visualiza-se a seguir:

Figura 1- Categoria Lugar

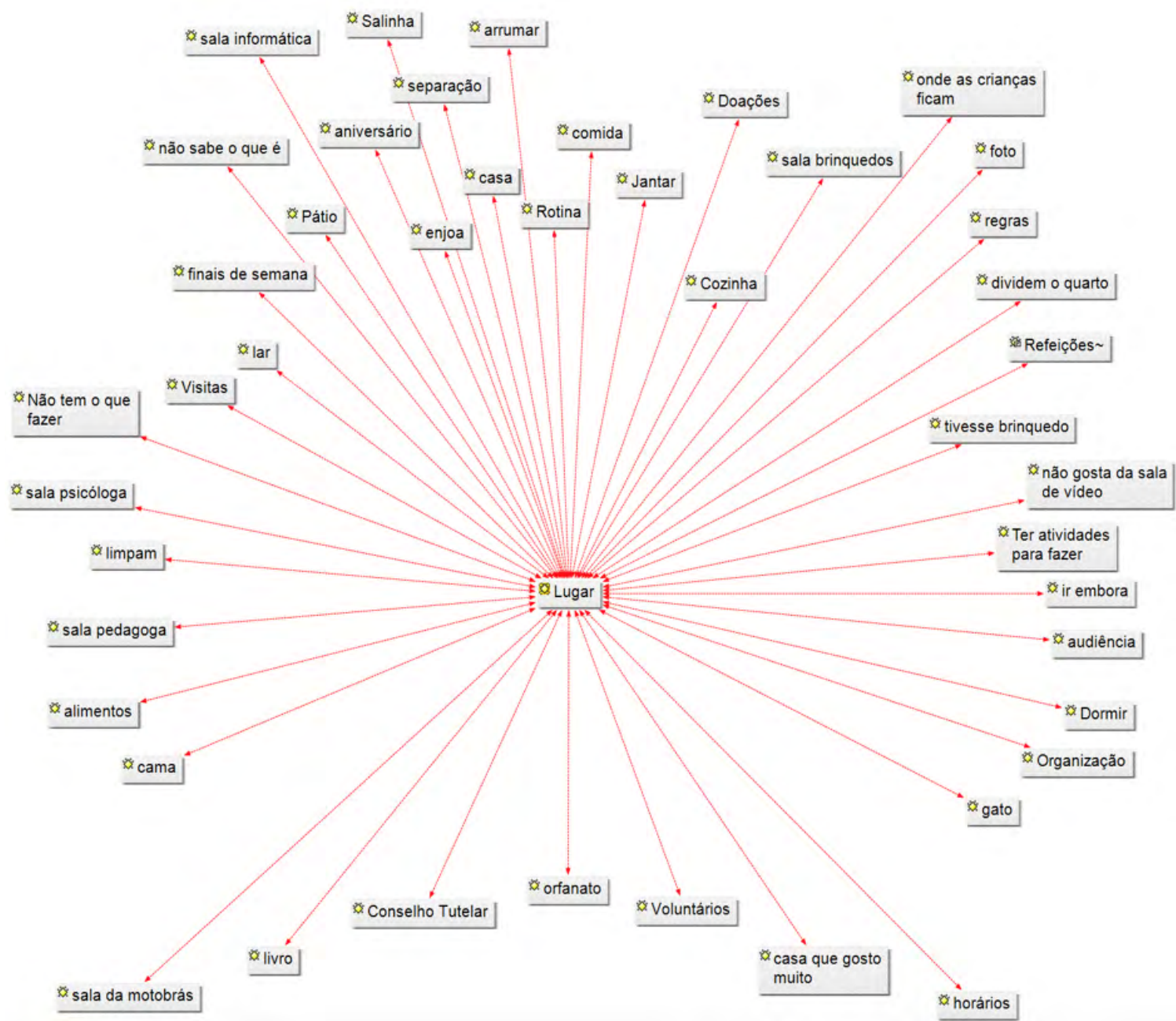

Fonte: Dados coletados da pesquisa, organizados com o software Atlas.Ti, 2016. 
Com a imagem anterior, além da categoria lugar físico, emergem as subcategorias, vindo ao encontro do que as crianças mencionaram sobre as duas instituiçóes de acolhimento. Nesse emaranhado de palavras, pode-se vislumbrar os nós que definem as instituições de acolhimento sobre o olhar das crianças e "o conhecimento de lugar acumula-se e transforma-se durante a vida, por meio do habitar, do ser e do modificarse em um lugar." (CHRISTENSEN, 2010, p. 148). Para melhor compreender o que pensam as crianças sobre o ambiente institucional, na Instituição 1 apresentamos o relato das duas crianças, a Maria Izabel e a Elizangela:

"O lugar que mais gostamos no orfanato é aqui, a sala... Dormimos na sala, algumas tias deixam, outras não [...] Aqui tem um gato chamado Meleca." (Elizangela).

"Vamos lá, tia, olha, aqui é o segundo lugar que gostamos mais. A avozinha faz comida boa pra nós. Tem a salinha, não gosto, fico só na sala e na cozinha, a Maria Izabel vai e brinca lá [...] Foi a tia que fez pra nós brinca, não tinha a salinha de brinca. Aqui é chato, não posso ir lá. Brincamos, olhamos a TV, vemos Pepa, Cúmplice de um Resgate, Carrossel. Vou pra escola pela manhã è à tarde faço aula de dança." (Maria Izabel).

Segundo as expressóes das crianças, a sala é o primeiro lugar de preferência e a cozinha é o segundo local que mais gostam, o que surge no diálogo da entrevista reflexiva e no registro fotográfico simultâneo. As manifestações surgiram após os acertos e alguns segredos que também foram revelados nas interpretaçóes das fotos pelas crianças. Algumas informaçóes serão mantidas como dados sigilosos da pesquisa. As instituições de acolhimento são ainda vistas como um lugar de disciplina, para seguir regras e rotinas. A partir das inserçóes realizadas nas instituições, dos diálogos e das fotografias, fica notório que as rotinas são construídas pelos profissionais e que muitas crianças não entendem o motivo de terem que permanecer num único local, no caso a sala de vídeo. Isso parece gerar desentendimentos e conflitos frequentemente.

$\mathrm{Na}$ Instituição 2, conforme anotaçóes em diário de campo, pudemos acompanhar a seguinte situação:

"Um grupo de 7 crianças foi visitar a Maria Izabel e não puderam entrar. Tentaram ficar conversando por entre as grades, o que também não era permitido. A criança acolhida pediu que os amigos entrassem, tentando questionar e burlar a regra. O desentendimento fez com que ela e uma educadora iniciassem uma discussão frente à imposição dessa ordem, que foi finalmente transgredida pela criança ao continuar 
conversando por entre as grades com os amigos, que não puderam entrar."(Diário de campo, setembro de 2015).

Em ocasióes que envolvem regras a serem cumpridas pelas crianças, os registros apontados mostram que elas enfrentam dificuldades em seguir normatizações. As rotinas nas duas instituiçóes de acolhimento pesquisadas não são idênticas, mas seguem uma rigorosidade nos horários que é típica e necessária aos ambientes institucionais. Entretanto, essas poderiam ser flexibilizadas em diálogos e negociaçóes entre os educadores e as crianças.

$\mathrm{Na}$ Instituição 1 as crianças que frequentam a escola pela manhã acordam às 7 horas: elas se arrumam, tomam café da manhã e são acompanhadas por uma educadora e o motorista até a escola, enquanto uma educadora fica de plantáo na instituição com as demais crianças e adolescentes, que permanecem dormindo até um pouco mais tarde (em torno das $8 \mathrm{~h} 30 \mathrm{~min}$ ). Após o café da manhá, podem ficar na sala e assistir televisão. As crianças que participam de atividades extraescolares são levadas por uma educadora e o motorista até o local, assim como são esses profissionais que as buscam nas escolas.

As crianças que precisam ir ao médico são acompanhadas por uma educadora e são atendidas por ordem de chegada, enquanto a outra educadora permanece na instituição com os demais acolhidos. $\mathrm{O}$ almoço é servido às $12 \mathrm{~h}$. Na rotina da tarde, as crianças são levadas pelo motorista e a educadora até a escola, que posteriormente vão pegá-las. Enquanto isso, os que permanecem na instituição ficam assistindo televisão, tomam café e fazem sua higiene pessoal. As educadoras que são professoras os ajudam com as tarefas escolares e os que náo precisam de ajuda ficam na sala de vídeo até o horário do jantar (20h30min). Logo, voltam à sala, ficam até aproximadamente $22 \mathrm{~h}$ acordados e, após, são convidados a irem dormir.

$\mathrm{Na}$ Instituição 2 a rotina se aproxima da entáo mencionada, apenas sendo diferente a pessoa que acompanha as crianças aos locais de fora da instituição. Nessa instituição 2 é o motorista que tem esse papel. Outra atividade que acontece de forma diferente é a realizada pela pessoa que ajuda nos temas, que nesse caso são duas pedagogas que trabalham em turnos alternados (uma pela manhã e a outra a noite). As crianças que náo têm compromisso pela manhã permanecem até mais tarde na cama e à noite vão dormir mais tarde também. As crianças alteram os locais que ficam durante o dia, algumas ficam na sala da Petrobrás ${ }^{5}$,

5 A instituição recebe doaçóes de várias empresas, no caso a escolha do nome da sala se deu pelo fato dela ser construída pela Petrobrás, na época. Mas as manutençóes são realizadas por outras empresas parceiras. Nesse ano, em outubro, a rede elétrica, pinturas, equipamentos e demais melhorias foi realizada por outra empresa, mas mesmo assim, as crianças e profissionais identificam a sala como salinha da Petrobrás. 
outras nos quartos, algumas nos corredores e outras na sala de vídeo. Podem, ainda, frequentar a Praça do Trabalhador ou a Praça Saraiva com as cuidadoras.

As Orientações Técnicas: Serviços de Acolhimento para Crianças e Adolescentes estabelecem que:

As crianças e adolescentes devem ter a oportunidade de realizar pequenas mudanças nos espaços privativos, fazer escolhas e de participar da organização do ambiente de acolhimento, segundo seu grau de desenvolvimento e capacidades. Assim, de modo gradativo e estritamente com função pedagógica, devem participar da organização da rotina diária do abrigo e assumir responsabilidade pelo cuidado com seus objetos pessoais, com seu auto-cuidado e cumprimento de compromissos (escola, atividades na comunidade, trabalho, etc. (BRASIL, 2009, p. 22).

As mudanças nas rotinas na Instituição I são comemoradas pelas crianças, o que vai ao encontro das Orientaçóes Técnicas. A expressão de contentamento da Maria Izabel, ao falar sobre as atividades realizadas na Instituição 1, é exemplo disso: "Ficamos aqui na sala, não fazemos quase nada, tia; eu e a Luana fizemos, nós decoramos o armário de chaves das tias e ficou legal, olha! Cada coisa no armário é para uma das tias. "Percebemos que, nas pequenas açóes realizadas nas instituiçóes de acolhimento pelas crianças, elas conseguem sentir-se parte do lugar: "[...] não há como conhecer ou sentir um lugar exceto estando nesse lugar e em posição de percebê-lo." (CHRISTENSEN, 2010, p. 147).

Nos relatos ora apresentados é visível a preocupação nas expressóes das crianças em fazer parte da construção das regras. Nesse desenfrear de ideários envolvendo os condicionantes socioambientais dos/entre lugares, podemos perceber os diferentes espaços que transitamos e construímos conhecimentos na/ com a educação ambiental entre/com os lugares, conforme Grün: “[...] estamos em busca da reapropriação social dos lugares e temos que cuidar para não cair no extremo oposto e obsolutizar os lugares.” (GRÜN, 2008, p. 8).

No caso das crianças institucionalizadas, ser e estar no mundo contemporâneo possibilita compreender o lugar institucional como circunstancialidade de um tempo vivido, de memórias, de dúvidas, de inquietaçóes que são e fazem esses lugares plurais e singulares. Esses lugares carregam as marcas de um período e de relaçóes que fazemos parte. Nas instituições de acolhimento esse conjunto aleatório se desenha num tempo e se constitui na memória e na complexidade das relaçóes sociais, políticas, econômicas e culturais que guardam e conduzem as memórias de uma sociedade. Nós nos constituímos no mundo, nas relaçóes sociais e são elas que nos empoderam 
a responder as inquietaçóes das vivências: "[...] é pelo lugar que nos identificamos, ou nos lembramos, constituindo assim a base de nossa existência no mundo." (MARANDOLA; HOLZER; OLIVEIRA, 2012, p. 228). Os espaços e lugares não são neutros e essa complexidade de ambientes que vivenciamos é uma teia de relações implicadas nos ambientes que estão num espaço. As reflexóes que seguem evidenciam a importância de conhecer os entre lugares e, assim, poder se sentir pertencente a eles, num movimento permanente de construção das rotinas institucionais. Não é possível chegar aos espaços sem se sentir pertencente aos lugares. Sáo esses espaços que fazem e constroem nossa identidade, nesses lugares singulares e plurais em que as crianças estão.

Importante ressaltar que, conforme demonstrado por vários diálogos estabelecidos com as próprias crianças e por suas declarações, a nomenclatura atribuída às instituiçóes de acolhimento pela maioria é orfanato. Das sete crianças participantes da pesquisa, seis delas se referem ao lugar como um lugar de orfandade: "[...] Aqui é orfanato." (Bob). Apenas uma criança não sabe: "Aqui é uma escola, aqui é Conselho Tutelar, é de livro, não sei o que é aqui." (Hills). Essa terminologia emerge no imaginário infantil, a despeito de o Estatuto da Criança e do Adolescente mostrar que a nomenclatura atribuída às instituiçóes é bem outra:

Serviço que oferece acolhimento, cuidado e espaço de desenvolvimento para grupos de crianças e adolescentes em situação de abandono ou cujas famílias ou responsáveis encontrem-se temporariamente impossibilitados de cumprir sua função de cuidado e proteção. (BRASIL, 1990, p. 67).

Diante do exposto, parece explícita a percepção das crianças que ficam nas instituiçôes de acolhimento, identificadas com um lugar de órfãos, da orfandade, no qual lhes foi imposto estar. Talvez elas realmente se sintam órfấs de suas famílias, parentes, comunidades, de seus endereços sociais. Na verdade, elas não sabem de fato quais são seus direitos, quais são as leis que as regulam, o papel e as atribuições do local que lhes é destinado estar por tempo indeterminado. Essas confusóes conceituais são percebidas nas falas de Hills ao dialogar sobre o lugar, quando se refere à escola ou ao Conselho Tutelar, apresentando total desconhecimento da nomenclatura e identidade do local, o que não difere das demais crianças, que reiteram que estáo em orfanatos, conforme Maria Izabel: "Aqui no orfanato náo podemos fazer muita coisa, a tia já disse que para ficar no orfanato temos que estudar."

A partir das inserçóes ecológicas planejadas, foi confirmado que as crianças usam a palavra orfanato e repetem o que escutam dos profissionais e dos familiares sobre o local que estão. O pai dos irmãos Hills, Bob e Princesa falou que ia tirar as crianças do orfanato, atribuindo a culpa deles ali estarem à figura da mãe. 
Podemos notar que a profissional também usou o mesmo termo, pois comunicou ao pai o cuidado que ele devia ter para "o dia da visita no orfanato, salientando que numa próxima visita aos filhos no orfanato fosse respeitado o dia. A ele seria permitida apenas a segunda-feira." (Diário de campo, setembro de 2015).

A questão acerca da percepção e uso do termo orfanato mobilizou uma breve pesquisa sobre a questão da orfandade no Brasil. Até os super-heróis, antes de serem super-heróis, passaram por situaçóes de risco e a maioria deles é órfão na infância. Posteriormente, nas histórias, esses personagens são adotados. Segundo os autores dessas ideias, fica demonstrada a escassez de publicaçóes sobre orfandade e conclui-se que, em geral, o sentido do conceito é de órfāos de pais (FRADKIN; WESCHENFELDER; YUNES, 2016). O significado de orfandade no dicionário também aponta que "[...] é a condição de quem é órfăo, o conjunto dos órfẫos, desamparo, quem perdeu o pai ou a mãe ou ambos, desprotegidos, abandonado." (HOUAISS, 2008, p. 543).

A etimologia da palavra traz o significado de abandono, de desamparo. Isso pode passar para as crianças como mensagens implícitas e, assim, elas acabam por sentir-se desamparadas, desatendidas e não acolhidas em suas necessidades. A metáfora que queremos enfatizar é que se percebemos o lugar de acolhimento como orfanato, ele náo deveria ser um lugar de disciplina e de cuidados básicos, mas sim de afetos. Um local que fisicamente prende, priva e tira a liberdade é um lugar de regras, de disciplina e dificilmente incentiva a convivência amorosa e generosa, como deveria ser um lócus de desenvolvimento de crianças e adolescentes.

O sentido do lugar no mundo contemporâneo institucional implica em rotina, conforme acompanhamos nas análises dos dados da pesquisa. A essa altura, indagamos: o lugar acompanha a criança ou a criança acompanha o lugar? As crianças produzem identidades para o local. Por isso, há que se compreender a relação intrínseca das expressóes das infâncias nas instituiçóes. Os lugares de relações são construções histórico-geográficas e em permanente construção e carregam consigo as marcas de um tempo vivido, formado pelo espaço e pelo tempo, lócus da experiência e da existência afetuosa na/com as infâncias, conforme acompanhamos nas expressóes das crianças acolhidas.

\section{Considerações finais}

A escassez de estratégias metodológicas que ofereçam oportunidades de dar voz e escutar atentamente as crianças durante o acolhimento institucional compóe o panorama contemporâneo dos estudos sobre os ambientes institucionais de acolhimento. Os tempos e espaços de convivência institucional nem sempre são 
temas fáceis para pesquisas, ainda mais quando se trata de infâncias. Diante desse fato, a presente pesquisa apostou numa metodologia dialógica e participativa. Enfatizou-se a potencialidade do uso da entrevista reflexiva associada ao registro fotográfico simultâneo e o diário de campo, compondo o alcance de uma linguagem verbal e visual, sempre no panorama individual, para preservar as subjetividades de cada um dos participantes. As fotos foram tiradas e interpretadas pelas próprias crianças durante a entrevista reflexiva num processo dialógico, participativo e ativo.

Os princípios da Teoria Fundamentada nos Dados com apoio do Atlas.Ti possibilitaram uma análise de dados igualmente dialógica, com menor risco de perder a base das informaçóes. Os ambientes muitas vezes são inibidores do que as crianças precisam e esperam vivenciar. Muitas vezes, as crianças não concordam com as regras e é muito difícil manter o silêncio. Os procedimentos utilizados deram voz às crianças e foram elas que nos contaram suas experiências e refletiram sobre suas percepçóes sobre o acolhimento.

As situaçóes em vários momentos nos surpreenderam ao trazer as falas das crianças, pois o conceito da voz das crianças é complexo. Os problemas socioambientais institucionais também são complexos, pois se referem às relaçóes humanas. Por isso, o ponto de partida foi o campo, a prática, a ação e a teorização pela implicação da pesquisadora alicerçada com a participação ativa das crianças.

Os acervos metodológicos utilizados como estratégias para ouvir as crianças tiveram forte papel na integração de ser e estar no ambiente pela presença constante, significativa e estável do pesquisador, decorrência da metodologia da inserção no contexto. O diálogo foi um movimento de transformação com metodologias associativas que, ao escutar as crianças, nos levou a três caminhos de categorias e subcategorias: elegemos o lugar institucional como um grande tema, seguido pela expressão das infâncias na instituição e pelas práticas relacionais no ambiente institucional. Todas essas temáticas são referentes às percepçóes das crianças sobre a instituição, como um lugar onde elas vivem.

Os resultados apontaram que as instituiçóes são percebidas como um lugar de disciplina, imposição de regras e ambivalências nas práticas educativas. O local é privado de liberdade, o acesso ao lúdico e as tecnologias são restritivas. Apesar da existência de rotinas, as crianças alegam que não conhecem as regras, o que é confirmado pelo relato da Elizangela: "As tias têm o caderno pra fazer queixa nossa e não podemos pegar." Compreendemos que há pouca organização das regras e comunicaçáo clara entre/com as crianças, de maneira que um fale, o outro escute e ambos construam aprendizagens significativas e participativas. As instituiçóes são pensadas pelos adultos e não levam em conta o ponto de vista das crianças, conforme as expressóes abaixo: 
“Temos computadores sem Internet." (Veterano).

"Aqui não fazemos nada e as tias não deixam usar o computador e aí fugimos pra falar com os cupinxas." (Maria Izabel).

"Tia, aqui elas só dizem não, escrevem de nós e aí nem sabemos. Só ficam ali vigiando o que fazemos e só vemos televisão, televisão e ainda nem podemos ver o que queremos." (Elizangela).

"Eu gosto da Tia N, que é a mais legal, lindona e da tia. Se meu irmão tivesse ali eu ia tira uma foto dele, mesmo não gostando de fica na salinha." (Bob).

"As tias sempre trocam os plantóes, aí vem umas que não pode nada." (Elizangela).

Constatamos que as controvérsias ocorrem, não apenas pela troca da tia, mas pelas ambivalências nas práticas de atendimento das tias, umas mais permissivas e outras mais coercitivas. As crianças trouxeram diferentes expressōes acerca das suas formas de ver o lugar, como: local de rotina, de disciplinas e de regras. Esses dados convergem com os estudos realizados por pesquisadores com crianças em instituições de acolhimento.

Portanto, fica evidente a diferença na maneira como os diversos profissionais dialogam e tratam as crianças, o que ainda depende da estrutura dos lugares físicos (por exemplo: na Instituição 1 há grades como impedimento para saídas e na Instituição 2 elas não existem). As instituiçôes não são compreendidas como um espaço de desenvolvimento, de expressão e de afeto e não são percebidas como um local de acolhimento pelas crianças. A maioria revelou que se sente num orfanato, pois parecem sentir-se órfãos de mães vivas diante da evidente quebra dos laços afetivos. Um lugar que não escolheram, mas que precisam ficar.

O movimento conceitual das infâncias nas instituiçóes foi marcado por um período de lutas e incertezas sobre o acolhimento, que atualmente protege e acolhe paralelamente, integrando a heterogeneidade das infâncias. Paradoxalmente, as discussóes com as crianças assinalaram o contrário. Nesse movimento transitório para uns e permanente para outros, pode-se concluir que a relação das crianças com o espaço do acolhimento é ainda uma incógnita para elas, já que pouco elas sabem sobre as rotinas, relaçóes e tempo de estada. Os relatos das crianças participantes nessa pesquisa comprovam essa constatação.

Os acervos metodológicos que dispomos na pesquisa possibilitaram olhar mais de perto as infâncias nas instituiçóes por meio dos olhos de quem está vivendo a condição de institucionalizado. Para pensar sobre as crianças é importante pensar COM as crianças, um movimento anunciado pelo Estatuto da Criança e do Adolescente (BRASIL, 1990), no qual as crianças são indiscutivelmente 
sujeitos de direitos. Por isso, a pesquisa foi enfática nesse ponto, no sentido de encontrar e estabelecer um diálogo com as crianças. Se o lugar onde elas vivem passa as silenciar, em vez de agitá-las, escutá-las, movimentá-las a correr e pular, isso pode ser uma consequência da ambivalência na conduta diante das regras.

As crianças afirmam: "Eu quero ter o direito de ir embora, ir para a casa, de ver meus amigos do lado de cá das grades.” A ação dos corpos inquietos, num movimento em permanente atividade entre os lugares singulares, carrega marcas dos condicionantes políticos, culturais, sociais, históricos e econômicos e constroem os ambientes. Assim, pular, ficar parado e quieto, seguir regras, chorar, correr, comer e gritar, entre outras expressóes humanas, devem emergir num universo de espontaneidade e efetivamente representar as infâncias nas instituições de acolhimento, bem como as infâncias em qualquer ambiente.

\section{Referências}

ARIZA, L; DIAS. V; SOUSA. R.; NUNES. B.; GALIAZZI, M. C.; SCHIMIDT, E. B. Articulaçóes metodológicas da análise textual discursiva com o Atlas. Ti compreensóes de uma comunidade aprendente. In: CONGRESSO EDUCAÇÃO 2015, 4., 2015, Aracaju. Proceedings... Congresso Ibero Americano em Investigação Qualitativa, Universidade Tiradentes, Aracaju Brasil, 2015. Disponível em: <http://proceedings.ciaiq.org/index.php/ciaiq2015/ article/view/273>. Acesso em: 10 dez. 2015.

ASSIS, S; FARIAS, L. Levantamento Nacional das Crianças e Adolescentes em Serviço de Acolhimento. São Paulo: Hucitec, 2013.

BARUDY, J.; DANTAGNAN, M. Los Buenos tratos alainfancia. Parentalidade, apego y resiliência. 3. ed. Barcelona: Gedisa Editorial, 2007.

BERNARDI, D. C. F. Cada caso é um caso. A voz das crianças e dos adolescentes em acolhimento institucional. Associação fazendo história: NECA- Associação dos Pesquisadores de Núcleos de Estudo e Pesquisa sobre a Criança e o Adolescente. 1. ed. São Paulo: 2010.

BRASIL, Ministério do Desenvolvimento Social e Combate à Fome. Estatuto da Criança e do Adolescente. Lei Federal no ${ }^{\circ}$ 8069, de 13 de julho de 1990.

BRASIL. Orientaçóes Técnicas: Serviços de Acolhimento para Crianças e Adolescentes. Brasília, DF: CNAS, CONANDA, 2009.

BRONFENBRENNER, U. A Ecologia do Desenvolvimento Humano. Experimentos naturais e planejados. 2. ed. Porto Alegre: Artes Médicas, 1996. 
CECCONELLO, A. M.; KOLLER, S. H. Inserção Ecológica na comunidade: uma proposta metodológica para o estudo de famílias em situação de risco. In: KOLLER. S. H. (Org.). Ecologia do desenvolvimento humano: pesquisa e intervenção no Brasil. São Paulo: Casa do Psicólogo, 2004.

CHARMAZ K. A. Construçáo da Teoria Fundamentada: guia prático para análise qualitativa. Porto Alegre: Artmed, 2009.

CORSARO, W. A. Sociologia da Infância. Tradução de Lia Gabriele Regius. Porto Alegre: Artmed, 2011.

CHRISTENSEN, P. Lugar, espaço e conhecimento: crianças em pequenas e grandes cidades. In: MÜLLER, F. (Org.). Infância em Perspectiva: políticas, pesquisas e instituiçóes. São Paulo: Cortez, 2010.

FRADKIN, C.; WESCHENFELDER, G.; YUNES, M. A. M. Comic superheroes are an untapped resource for empowering vulnerable children. Child Abuse \& Neglect, 51, p. 407- 415, 2016. Disponível em: <https://www.researchgate.net/ publication/283711314_shared_adversities_of_children_and_comic_superheroes_ as_resources_for_promoting_resilience>. Acesso em: 29 jan. 2016.

FREIRE, P. Pedagogia da Autonomia: saberes necessários à prática educativa. São Paulo: Paz e Terra, 1996.

GARZELLA, M. O abrigo sob a perspectiva da criança. Monografia de Conclusão (Bacharelado em Psicologia). Faculdade de Filosofia, Ciências e Letras de Ribeirão Preto, Universidade de São Paulo, Ribeirão Preto, 2008.

GLASER, B. G.; STRAUSS, A. L. Discovery of grounded theory: Strategies for qualitative research. Chicago: Aldine, 1967.

GRÜN, M. A importância dos lugares na Educação Ambiental. Revista Eletrônica do Mestrado em Educaçáo Ambiental. ISSN 1517-1256, v. especial, dez. 2008. Disponível em: <https://www.seer.furg.br/remea/article/view/3384/2030>. Acesso em: 12 dez. 2015.

HOUAISS, A. Minidicionário Houaiss da língua portuguesa. 3. ed. rev. e aum. Rio de Janeiro: Objetiva, 2008.

MARANDOLA, J.; HOLZER W.; OLIVEIRA L. Qual o espaço do lugar? Geografia, epistemologia, fenomenologia. São Paulo: Perspectiva, 2012.

MARZOL, R. M.; BONAFÉ, L.; YUNES, M. A. M. As Perspectivas de crianças e adolescentes em situação de acolhimento sobre os cuidadores protetores. Revista Psicologia, Porto Alegre, v. 43, n. 3, jul/set. 2012. 
MINAYO, M. Pesquisa Social: Teoria, Método e Criatividade. 6. ed. Petrópolis: Editora Vozes, 1996.

PRATI, E.; COUTO M. C. P.; MOURA, A.; POLETTO, M.; KOLLER, S. H. Revisando a Inserção Ecológica: uma proposta de sistematização. Psicologia: Reflexão e Crítica, v. 21, n. 1, p. 160-169, 2008. Disponível em:<https://www.scielo.br/prc>. Acesso em: 10 abr. 2015.

SAN MARTÍN, D. Teoría Fundamentada y Atlas.ti: recursos metodológicos para la investigación educativa. Revista Electrónica de Investigación Educativa, v. 16, n. 1, p. 104-122, 2014.

SILVA, F. L.; MAGALHÂES, L. A. "Assistir Robocop lá é chato!" Conversando com crianças sobre suas vivências no abrigo institucional. ROSSETTI-FERREIRA, $M$. A; SERRANO, S. A; ALMEIDA, I. G. (Coord.). O acolhimento institucional na perspectiva da criança. São Paulo: Hucitec, 2011.

SILVEIRA, S. A. B.; GARCIA. N. M.; PIETRO A. T.; YUNES, M. A. M. Inserção Ecológica: metodologia para pesquisar risco e intervir com proteção. Psicologia da Educaçáo, n. 29, São Paulo, 2009. Disponível em:<http://pepsic. bvsalud.org/scielo.php?script=sci_arttext\&pid=S1414-69752009000200004>, acesso em: 15 nov. 2015.

SIQUEIRA, A.; DELL'AGLIO, D. O impacto da institucionalização na infância e na adolescência: uma revisão de literatura. Psicologia \& Sociedade [online], v. 18 , n. 1, p 71-80, jan./abr. 2006. Disponível em: <http://www.scielo.br/scielophp.dx.doi. org/10.1590/S0102-71822006000100010>. Acesso em: 15 nov. 2015.

STRAUSS, A.; CORBIN, J. Grounded Theory Research: Procedures, Canons and Evaluative Criteria. Qualitative Sociology, v. 13, n. 0.t, 1990.

SZYMANSKI, H. A entrevista na educaçáo: a prática reflexiva. 2. ed. Brasília, DF: Liber Livro, 2004.

YUNES, M. A. M.; SZYMANSKI, H. Grounded-Theory e a entrevista reflexiva: uma associação de estratégias metodológicas qualitativas para a compreensão da resiliência em famílias. In: GALIAZZI, M. C.; FREITAS, J. V. Metodologias emergentes de pesquisa em educaçáo ambiental. Ijuí: Ed. Unijuí, 2005.

YUNES, M. A. M. A questáo triplamente controvertida da resiliência em famílias de baixa renda. Tese (Doutorado em Psicologia) - Pontifícia Universidade Católica de São Paulo, São Paulo, 2001. 